\title{
Towards better representations of carbon allocation in vegetation: a conceptual framework and mathematical tool
}

\author{
Verónika Ceballos-Núñez ${ }^{1}$ - Markus Müller ${ }^{1} \cdot$ Carlos A. Sierra $^{1}$ \\ Received: 8 April 2019 / Accepted: 3 March 2020 / Published online: 22 April 2020 \\ (C) The Author(s) 2020
}

\begin{abstract}
The representation of carbon allocation (CA) in ecosystem differs tremendously among models, resulting in diverse responses of carbon cycling and storage to global change. Several studies have highlighted discrepancies between empirical observations and model predictions, attributing these differences to problems of model structure. We analyzed the mathematical representation of CA in models using concepts from dynamical systems theory; we reviewed a representative sample of models of CA in vegetation and developed a model database within the Python package bgc-md. We asked whether these representations can be generalized as a linear system, or whether a more general framework is needed to accommodate nonlinearities. Some of the vegetation systems simulated with the reviewed models have a fixed partitioning of photosynthetic products, independent of environmental forcing. Vegetation is often represented as a linear system without storage compartments. Yet, other structures with nonlinearities have also been proposed, with important consequences on the temporal trajectories of ecosystem carbon compartments. The proposed mathematical framework unifies the representation of alternative CA schemes, facilitating their classification according to mathematical properties as well as their potential temporal behaviour. It can represent complex processes in a compact form, which can potentially facilitate dialog among empiricists, theoreticians, and modellers.
\end{abstract}

Keywords Carbon allocation $\cdot$ Ecosystem models $\cdot$ Nonlinearities $\cdot$ Compartmental systems

\section{Introduction}

Current and expected changes in climate and atmospheric $\mathrm{CO}_{2}$ concentration have prompted the study of the mechanisms used by vegetation to survive to changing environmental conditions. One of these mechanisms is the adjustment of their carbon allocation scheme (Lacointe 2000; Franklin et al. 2012; Xia et al. 2017). Carbon allocation is a concept that involves all carbon cyclerelated processes that take place within vegetation such as the following: the assimilation of atmospheric $\mathrm{CO}_{2}$

Electronic supplementary material The online version of this article (https://doi.org/10.1007/s12080-020-00455-w) contains supplementary material, which is available to authorized users.

Verónika Ceballos-Núñez

vceball@bgc-jena.mpg.de

Carlos A. Sierra

csierra@bgc-jena.mpg.de

1 Max Planck Institute for Biogeochemistry, Hans-Knöll-Str. 10, 07745, Jena, Germany via photosynthesis; the partitioning of the photosynthetic assimilates to vegetation parts (from here on compartments) for growth or for other processes such as maintenance, defence, and storage; and the time carbon atoms remain in the vegetation before being released back to the atmosphere (Lacointe 2000; Schimel et al. 2001; Trumbore 2006; Canadell et al. 2007; Franklin et al. 2012; Körner 2017). Although these processes take place in different spatial and temporal scales, they are interconnected.

Photosynthesis, for example, is a metabolic pathway that takes place in the chloroplast and requires light, $\mathrm{CO}_{2}$, and water. The amount of captured light available for photosynthesis depends on molecules (pigments) whose abundance is determined by the phenological state of the plant; e.g. deciduous plants have green leaves at the beginning of the growing season because they are rich in chlorophyll (pigment that can absorb blue and red lights); thus, when it is no longer produced and is broken down (in autumn), the leaves take the colors of the remaining pigments, which are not as efficient absorbing light. Ontogeny also plays an important role, because older plants have slower metabolism than younger ones (Hartmann et al. 2018). In addition, not all leaves in a plant are exposed 
to the same quantity and quality of light simultaneously, some may be shaded by other leaves of the same plant or competing plants, creating heterogeneity in photosynthetic rates. Thus, the amount of light available for photosynthesis at the ecosystem scale depends on the capacity of the canopy to intercept light, quantified by the leaf area index (LAI), i.e. the sum of all leaf layers in a canopy (Waring and Running 1998). For reviews on plant-environment interactions across scales refer to Waring and Running (1998), Reichstein et al. (2014), Hartmann and Trumbore (2016), and Hartmann et al. (2018).

It is then evident that the metabolic activities that occur at short spatial and temporal scales depend on precursors whose availability is determined by processes taking place at larger scales, such as competition for light, water, and other resources. Unfortunately, not all processes involved are understood at the same level of detail and, or spatio-temporal resolution, which creates opportunities for multiple interpretations and uncertainties for upscaling in models. This is problematic because if processes are addressed with a different level of detail, there is an unbalanced representation of reality (Waring and Running 1998), and this biased representation can lead to inconsistent predictions (Govingjee 2009). In fact, coupled climate-carbon cycle models predict divergent trajectories of future fluxes among Earth's major carbon reservoirs, with no consensus on whether terrestrial ecosystems will act as a net source or sink of carbon with respect to the atmosphere (Friedlingstein et al. 2006; Friedlingstein et al. 2014).

The effort to reconcile diverse empirical findings and attain realistic predictions has prompted the use of a large number of functions and parameters in models (Quaiser et al. 2011). However, many parameter values are unknown because they are not necessarily measurable (Trumbore 2006), and increasing model complexity has obscured the identification of the main processes that control overall system behaviour. Perhaps this is why the quest to find the source of uncertainties has been limited to the comparison of numerical outputs of models (De Kauwe et al. 2014), and reviews of their conceptual design (Franklin et al. 2012; Walker et al. 2014; Merganičová et al. 2019; Trugman et al. 2019). Although these studies have inspired model classifications (e.g. based on the carbon allocation scheme: static or dynamic ${ }^{1}$ (Litton et al. 2007)) that can indicate potential predictive uses of a model (until a certain extent), these conceptual classifications can be ambiguous.

We identified two main sources of ambiguity in the description of CA in models. The first source is that despite previous attempts to clarify terminology, the concept of

\footnotetext{
${ }^{1}$ Dynamics is a term used for time-evolutionary phenomena or the part of mathematical science that is used for the representation and analysis of such phenomena (Luenberger and Hill 1979).
}

carbon allocation is still being used to describe both, patterns and processes, which leads to an ambiguity originally exposed by Litton et al. (2007); carbon allocation is a general term that overarches patterns (biomass) and processes (flux and partitioning) according to Litton et al. (2007). As an example, the sentence the carbon allocated to the vegetation compartment $X$ may have three different interpretations depending on the context: (i) the amount of carbon present in $X$ at a certain time (biomass), (ii) the portion of photosynthetic input that goes to $X$ (partitioning), and (iii) the flux of carbon into and out of $X$. The second source of ambiguity is that it is unclear if the term dynamic carbon allocation, which is commonly used in the modelling literature, implies dynamic functions for fluxes, or for partitioning of photosynthetic input. As we will show later, there are important consequences on carbon storage, cycling, and release due to the introduction of these assumptions. In addition, since the former classifications are only based on 'descriptive rather than analytic' assessments of models (Xia et al. 2013), they ignore the implications that their mathematical representations may have on predicted dynamics.

Evidently, the assessment of the mathematical representations of carbon allocation (model structure) is of major importance; while the parameter nonidentifiability and a wrong choice of modelling approach are undeniable causes of poor model performance, an important cause of error in models involves problems with model structure. Some characteristics of model structures can help to identify a priori certain model behaviours, e.g. the stability of the system modelled. It is important to identify whether a system is in steady state or not because that is a prerequisite for the calculation of certain model performance diagnostics (Sierra et al. 2016). The analysis of the model's stability can also have a tremendous impact in the perception of its resilience, i.e. the maximum perturbation that can be taken without causing a shift to an alternative stable state.

There are other types of behaviours such as hysteresis loops, oscillations, and multiple steady states (Strogatz 2014), which have important consequences for the stability and the resilience of a system, and can be the result of nonlinear interactions. Nonlinearities occur when certain types of interactions between the parts of the modelled system (e.g. interference, cooperation, and competition) are symbolized mathematically with nonlinear terms such as products and powers (Strogatz 2014).

Overall, a better understanding of model structure can contribute to develop concrete criteria for selecting relevant modelling approaches and performance diagnostics. However, the comparison of the mathematical formulation of multiple models is impaired by the fact that they are encoded in different (often cryptic) programming languages, and the published model descriptions do not follow 
a standard such as the ODD (Overview, Design concepts, and Details) protocol (Grimm et al. 2006; Grimm et al. 2010). But perhaps the main caveat is that when equations are presented as lists or sets, the interactions between variables are not conspicuous. Thus, it is not always clear if there are dependencies between variables that can lead to structural nonidentifiabilities (Raue et al. 2009). This is why the general matrix model of the terrestrial carbon cycle (see Eq. 1) was a leap forward in the field (Luo et al. 2003; Luo et al. 2012). It can be expressed as

$$
\begin{aligned}
\frac{d X(t)}{d t} & =A \xi(t) C X(t)+B U(t), \\
X(t=0) & =X_{0}
\end{aligned}
$$

where $X(t)$ is a vector of ecosystem carbon pools, $\xi$ is a scalar representing effects of temperature and moisture on the carbon transfer among pools, $A$ and $C$ are matrices containing carbon transfer coefficients between plant, litter, and soil pools, $B$ is a vector of partitioning coefficients of the photosynthetically fixed carbon to plant pools, $U(t)$ is the photosynthetically fixed carbon, and $X_{0}$ is a vector of initial values of the carbon pools (see also Fig. 1). Within this framework, the modelled terrestrial $\mathrm{C}$ storage capacity can be decomposed into a few traceable components that are built upon biogeochemical principles.

Although this matrix equation has an important role mapping the mathematical formulations to the modelled biogeochemical processes, it has a few limitations: the partitioning coefficients $(B)$ are fixed; and it does not allow for nonlinear interactions such as the case when photosynthetic rates depend on the storage of carbon in other compartments. This is problematic because complex systems such as terrestrial ecosystems are not necessarily linear (Luenberger and Hill 1979; Zobeley et al. 2005). In fact, certain nonlinearities have been revealed when there is competition for light in models that can accurately predict productivity and species composition (Purves and Pacala 2008). Thus, it is necessary to define a new framework that (a) has more flexibility to accommodate different types of inputs (e.g. C assimilation rate, Gross Primary Productivity-GPP, Net Primary Productivity-NPP); (b) allow for a dynamic partitioning of inputs or storage reserves; and (c) can accommodate nonlinearities among system components.

In this contribution, we studied the process of CA in vegetation at the ecosystems level, from a dynamical systems perspective. We addressed the following questions: (1) How can we express the carbon allocation concept within the context of dynamical systems? (2) Is there a mathematical framework that can accommodate nonlinearities? (3) Can we systematically identify common model properties and categorize the models accordingly? We reviewed published model descriptions and constructed a database with a selection of them. This database aided us during the analysis of

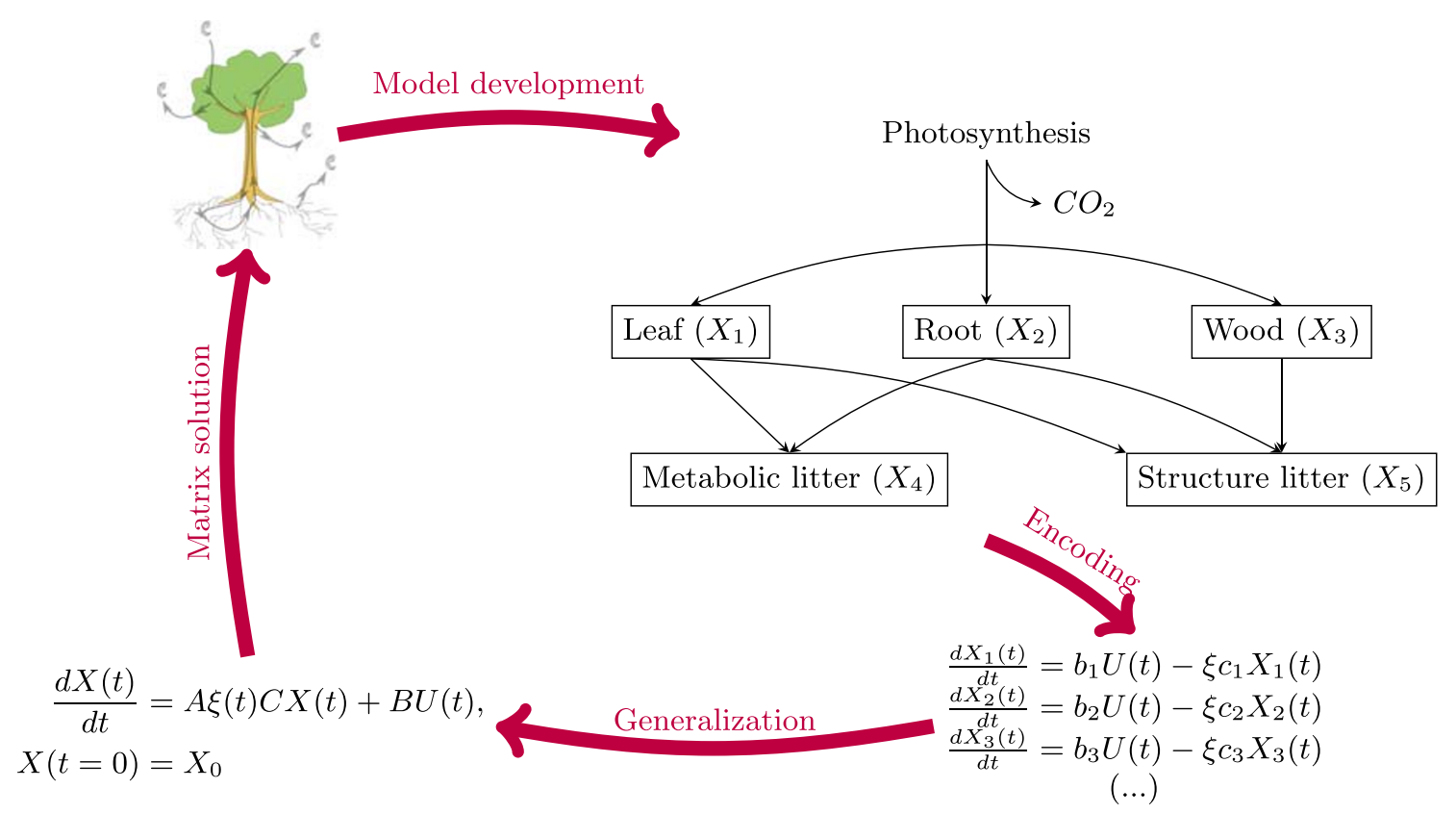

Fig. 1 Matrix approach to carbon cycle modelling (Luo et al. 2003). Empirical observations inspire model development, and the models can be encoded using ordinary differential equations. These equations can be generalized into a matrix representation, which in turn can be used to evaluate how the $\mathrm{C}$ sinks vary with environmental forcing over time. $X(t)$ is a vector of ecosystem carbon pools, $\xi$ is a scalar representing effects of temperature and moisture on the carbon transfer among pools, $A$ and $C$ are carbon transfer coefficients between plant, litter, and soil pools, $B$ is a vector of partitioning coefficients of the photosynthetically fixed carbon to plant pools, $U(t)$ is the photosynthetically fixed carbon, and $X_{0}$ is a vector of initial values of the carbon pools. Adapted from http://www.cesm.ucar.edu/events/wg-meetings/ 2017/presentations/bgcwg+lmwg/luo.pdf 
the sets of equations that represent $\mathrm{CA}$ in vegetation. Based on this model synthesis, we were able to identify key characteristics from which we inferred the proposed conceptual framework and mathematical tool.

\section{Methods}

This study is a comprehensive analysis of the common mathematical expressions used to model CA in vegetation. We synthesized different mathematical expressions used to represent CA in models taking advantage of the mathematical concept of dynamical system. This concept is a general abstraction to describe a rule that determines the future behaviour of a set of variables based on their current state (Luenberger and Hill 1979). Thus, in a dynamical system, the patterns from the present are a result from the patterns in the past. These time linkages among variables can be represented using difference or differential equations depending on whether the dynamic behaviour occurs in discrete or continuous time, respectively. A difference equation relates the value $y(k)$, at point $k$, to values at other points (e.g. $y(k+1)=a y(k), k=0,1,2, \ldots)$. A differential equation connects a function $y(t)$ defined on an interval of continuous time and some of its derivatives. For further details on these concepts, please refer to Luenberger and Hill 1979, p. 27.

\section{Working definition of carbon allocation}

In order to avoid the ambiguities mentioned in the 'Introduction' section, we contextualized the CA concept within the more general theory of dynamical systems and modify the matrix representation from Eq. 1 as follows:

$f=u \cdot \beta+\boldsymbol{B} \cdot \mathbf{x}$

where $f$ is a function valued vector that relates the changing quantities that take place between the vegetation compartments; $u$ is a scalar function that represents the primary productivity — system input—and may be an assimilation rate, GPP, or NPP; $\beta$ is a vector containing the partitioning coefficients of photosynthetic input; $\boldsymbol{B}$ is a matrix that contains the carbon transfer coefficients between plant, litter, and soil compartments; and $\mathbf{x}$ is a vector of states for vegetation (state variables). This is illustrated with an example of a two-compartment system (Fig. 2).

Based on this new representation, we propose the following definition: Carbon allocation is the balance (net flux) of the $\mathrm{C}$ flows into, between, and out of the vegetation compartments, because the amount of carbon in a single compartment at a given time $(t)$ is the balance between the $\mathrm{C}$ that has flown into and out of this compartment. This definition makes it possible to distinguish between the different cases constantly grouped as carbon allocation by assigning each case to its corresponding term in Eq. 2 as follows: (a) 'the $\mathrm{C}$ in $X$ ' refers to the biomass: $x$; (b) 'the C partitioned to $X$ ' is the fraction of the input that goes to that compartment, i.e. partitioning: $\beta$; and (c) 'the carbon allocated to $X$ ' is the result of the whole process, i.e. the net flux: right hand side of the Ordinary Differential Equation (ODE) 2.

This definition was the result of the review of several published model descriptions and is the basis of the mathematical framework that we propose and use to further analyze the main characteristics of the model descriptions (e.g. driving variables ${ }^{2}$, parameters ${ }^{2}$, nonlinearities). The organization of the equations within this framework also facilitates the identification of rates ([time $\left.\left.{ }^{-1}\right]\right)$, fractions ([], unitless), and fluxes ([mass.time $\left.{ }^{-1}\right]$ ), just by observing their units. As means to automate the analysis of published model descriptions (PMDs) and promote the use of this framework to understand the representation of $\mathrm{CA}$ in models, we developed a model database and an accompanying Python 3 package called bgc-md.

\section{Selection of published model descriptions}

We reviewed PMDs of ecosystem models and extracted the equations and descriptions contained in their CA module. Our literature search was not exhaustive, but we obtained a representative sample of PMDs by focusing our selection to published reviews (Franklin et al. 2012; De Kauwe et al. 2014; Walker et al. 2014), and Web of Science. The search in Web of Science took place in February 2020, using the following keywords: models, simulations, environmental sciences, and carbon allocation; we found 167 published articles from which we selected only those that had a complete description of the module of carbon allocation in vegetation, where processes were represented using ordinary differential equations (ODEs) with a consistent use of symbols.

\section{Protocol for analyzing the PMDs using the Python package bgc-md}

The Python 3 package, bgc-md (https://github.com/ MPIBGC-TEE/bgc-md) consists of a model database and additional code that (i) extracts the information from each

\footnotetext{
${ }^{2}$ Variable is a model attribute that changes during the model simulation. A parameter is a model attribute (e.g. rates) that does not change during the model simulation. Note that some factors that have been called parameters (e.g. soil moisture...) but actually are dynamic (are functions of time or other variables) are indeed variables (http://web.hwr.arizona.edu/hwr642/Generic/ Content/Definitions/DefinitionsText.html and http://www.math.tamu. edu/ phoward/m647/modode.pdf).
} 


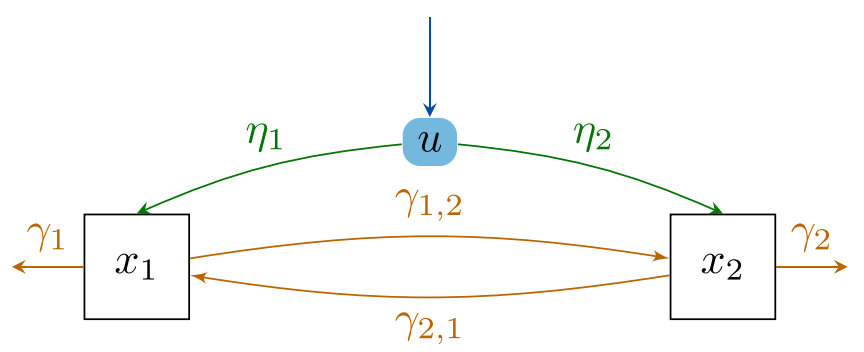

\begin{tabular}{|c|c|c|c|c|}
\hline \multirow{3}{*}{$\begin{array}{c}\text { Pools } \\
\dot{x}_{1}\end{array}$} & & \multicolumn{3}{|c|}{ Fluxes } \\
\hline & & Inflows & & Outflows \\
\hline & $=$ & $u \cdot \eta_{1}+\gamma_{2,1} \cdot x_{2}$ & - & $\left(\gamma_{1}+\gamma_{1,2}\right) \cdot x_{1}$ \\
\hline$\dot{x}_{2}$ & $=$ & $u \cdot \eta_{2}+\gamma_{1,2} \cdot x_{1}$ & - & $\left(\gamma_{2}+\gamma_{2,1}\right) \cdot x_{2}$ \\
\hline
\end{tabular}

$$
\begin{aligned}
\boldsymbol{f} & =u \cdot \boldsymbol{\beta}+\mathbf{B} \cdot \boldsymbol{x} \\
\left(\begin{array}{l}
\dot{x}_{1} \\
\dot{x}_{2}
\end{array}\right) & =u \cdot\left(\begin{array}{l}
\eta_{1} \\
\eta_{2}
\end{array}\right)+\left(\begin{array}{cc}
-\left(\gamma_{1}+\gamma_{1,2}\right) & \gamma_{2,1} \\
\gamma_{1,2} & -\left(\gamma_{2}+\gamma_{2,1}\right)
\end{array}\right) \cdot\left(\begin{array}{l}
x_{1} \\
x_{2}
\end{array}\right)
\end{aligned}
$$

$\left[\right.$ mass $\cdot$ area $^{-1} \cdot$ time $\left.^{-1}\right]=\left[\right.$ mass $\cdot$ area $^{-1} \cdot$ time $\left.^{-1}\right] \cdot \bigcirc+\left[\right.$ time $\left.\left.^{-1}\right]\right] \cdot\left[\right.$ mass $\left._{\text {area }}{ }^{-1}\right]$

Fig. 2 General mathematical representation of carbon allocation (CA) in a 2-compartment vegetation model. The colors facilitate the identification of the different modules; grey: entire CA process, blue: photosynthetic input, green: partitioning of the input, and orange: $\mathrm{C}$ transfers between and out of the compartments. The arrows point towards the direction of the movement of the compartment content. The letters above them symbolize the parameters that regulate this flux. Other symbols are $\mathbf{x}$ : vector of states for vegetation (state variables); $\dot{\mathbf{x}}=d \mathbf{x} / d t$ : changing quantity of vegetation compartment $x$ with respect to time (state variables $x_{1}$ and $x_{2}$ ); $f$ : function valued vector

database entry, (ii) generates reports, and (iii) performs computations such as model runs, calculation of jacobian and eigenvalues, and generates various plots for comparison. The entries in the database consist of text files written in YAML format (www.yaml.org). Each entry corresponds to a selected publication-PMD and is created as follows:

1. The first lines of an entry are the metadata, i.e. the information needed in order to identify the model, the author of the entry, the publication where it came from, and some model characteristics such as the partitioning scheme (fixed or dynamic) and whether it was claimed that the model prioritizes a compartment during partitioning, or not. The doi of the original publication is also included in order to automatically generate citations using the API from crossref (www.crossref.org). that relates the changing quantities that take place between the vegetation compartments; $u$ : scalar function that represents the primary productivity—system input — and may be an assimilation rate, GPP, or NPP; $\beta$ : vector containing the partitioning coefficients of photosynthetic input; $\boldsymbol{B}$ : carbon transfer coefficients between plant, litter, and soil compartments. The matrix representation was derived as described in Anderson (1983) and Sierra et al. (2012). The last equation shows the units that the different components may have, highlighting their participation as fluxes $(f, u)$, coefficients -fractions- $(\beta)$, and rates $(\boldsymbol{B})$ in the model

2. After the metadata, there is a section called 'model', which is divided into subsections (e.g. state variables, photosynthetic parameters) that consist of a list of symbols that represent variables or parameters. If the function to calculate a variable is provided (e.g. NPP $=\mathrm{GPP}-\mathrm{R})$, the equation is written using symbolic mathematics according to the syntax of the python package SymPy (Meurer et al. 2017).

The final component of the 'model' section is the subsection 'components'. Here the sets of ODEs are factorized into the matrix form of Eq. 2 (see also Fig. 2).

3. The bgc-md package computes the equations in the matrix form and produces reports in html format. These reports summarize the PMDs and display the set of equations in a readable way. In order to allow a quick comparison of a list of models, the package can also generate a website with reports and graphs that can be navigated. 


\section{Code availability}

All of the simulations and figures for this work can be reproduced using the code and data provided in the supplementary material.

\section{Results}

From a total of 182 reviewed publications, only a few of them (19) met the requirements of having a CA scheme described with a complete set of difference or differential equations (Table 1). Evidently, we did not include PMDs without equations (e.g. Chen and Reynolds 1997). Other types of publications excluded from our review were those concerned with aquatic vegetation (e.g. Soetaert et al. 2004), tree ring simulations (e.g. Eglin et al. 2010; Lazzarotto et al. 2009; Li et al. 2014), pipe models (e.g. Valentine 1999; Schiestl-Aalto et al. 2015; Falster et al. et al. 2017), annual plants (e.g. Fox 1992a), vegetation systems with two compartments or less (e.g. Huntingford et al. 2000), and models that represented the carbon allocation using allometric equations (e.g. Weng et al. 2019) or structural equation modelling (e.g. Hofhansl et al. 2014).

The vegetation systems described in the PMDs correspond to different hierarchies, ranging from individual plants ( 2 models), to forests (4 models), regions (3 models), up to the whole globe (10 models). In terms of time resolution, the processes described in the PMDs often take place at different scales; there can be daily simulations of photosynthesis, evapotranspiration, and soil water dynamics, and annual updates of vegetation structure and plant functional type population densities (Sitch et al. 2003). Another example of such a wide time-scale range was observed in the model Tethys-Chloris by Fatichi and Leuzinger (2013), in which the photosynthesis, energy, and water fluxes are resolved hourly, and the 'carbon allocation' and turnover take place at a daily time step. This means that the input $(u)$ of these models is often portrayed as a faster process than the partitioning $(\beta)$ and cycling $(\boldsymbol{B})$.

Moreover, different modelling approaches (conceptual and mathematical) have been used to simulate CA as a whole, and the partitioning in particular. Table 2 summarizes the main groups in which the models can be classified according to these different approaches. Our contribution to this classification, which builds on the previous work of De Kauwe et al. (2014) and Walker et al. (2014), is a classification based on the mathematical formulation of CA $(f(\mathbf{x}, t))$, derived from the fact that several models have been described using linear ODEs, nonlinear ODEs, or difference equations.

Our literature search revealed that in 11 of the 19 PMDs selected, it was claimed that they had a 'dynamic carbon allocation' because their objective was to simulate the vegetation response to environmental cues (e.g. lack of water or light) via selective partitioning of newly photosynthesized carbon to a limiting compartment. However, three of these 11 had a fixed partitioning scheme (fixed coefficients) and the environmental scalars were only found in the photosynthesis or turnover modules (see Table 1). Within such a scheme, the changes in environmental conditions only affect the amount of $\mathrm{C}$ entering or leaving the system as a whole, i.e. the limiting compartment would not be favoured in the partitioning of C. This is an example of how alternative interpretations of the term 'dynamic carbon allocation' can lead to misleading or ambiguous model descriptions.

This supports the need to use the working definition of CA proposed in the methods to continue with our analysis, leaning on the biogeochemical relevance of the terms in Eq. 2 (photosynthetic input- $u$, partitioning- $\beta$, cycling- $\boldsymbol{B}$, and stocks (state variables)-x). For this reason, we analyzed the components of each term instead of searching for connections between numerous equations spread across modules (e.g. stomata, physiology, canopy, carbon balance), which is a very common way to organize the equations in ecosystem models. Identifying these connections, and especially the type of interactions between variables and parameters is important because some dependencies between state variables can lead to nonlinearities.

In light of this working definition, we could find the characteristics that the 19 PMDs had in common, such as their driving variables and their interactions. We found that in 14 of the 19 PMDs, there is a lack of carbon exchange between the vegetation compartments. This characteristic was diagnosed by the bgc-md package, which automatically identified that their cycling matrix $\boldsymbol{B}$ is diagonal-the elements of the off diagonal are zeros (see Table 1). Moreover, the only cases in which the compartments exchange $\mathrm{C}$ is when there is a labile $\mathrm{C}$ compartment, e.g. the model DALEC (Williams et al. 2005).

Furthermore, we found two distinct ways to represent respiration in vegetation: (a) growth respiration is often portrayed as a percentage of the $\mathrm{C}$ influx, which is a calculation performed within $u$ independently from the amount of $\mathrm{C}$ stored in the compartments; in contrast, (b) maintenance respiration is a flux that depends on the amount of $\mathrm{C}$ stored, because it is the product of the multiplication of state variables and cycling rates $(\boldsymbol{B} \cdot \mathbf{x})$. These two representations have different implications. In case (a), respiration represents the cost of growing organs, which is the amount of photosynthetically fixed $\mathrm{C}$ that cannot be used to build new tissues. In case (b), respiration is the metabolic cost of maintaining the existent tissue, which depends on how much tissue there is. 


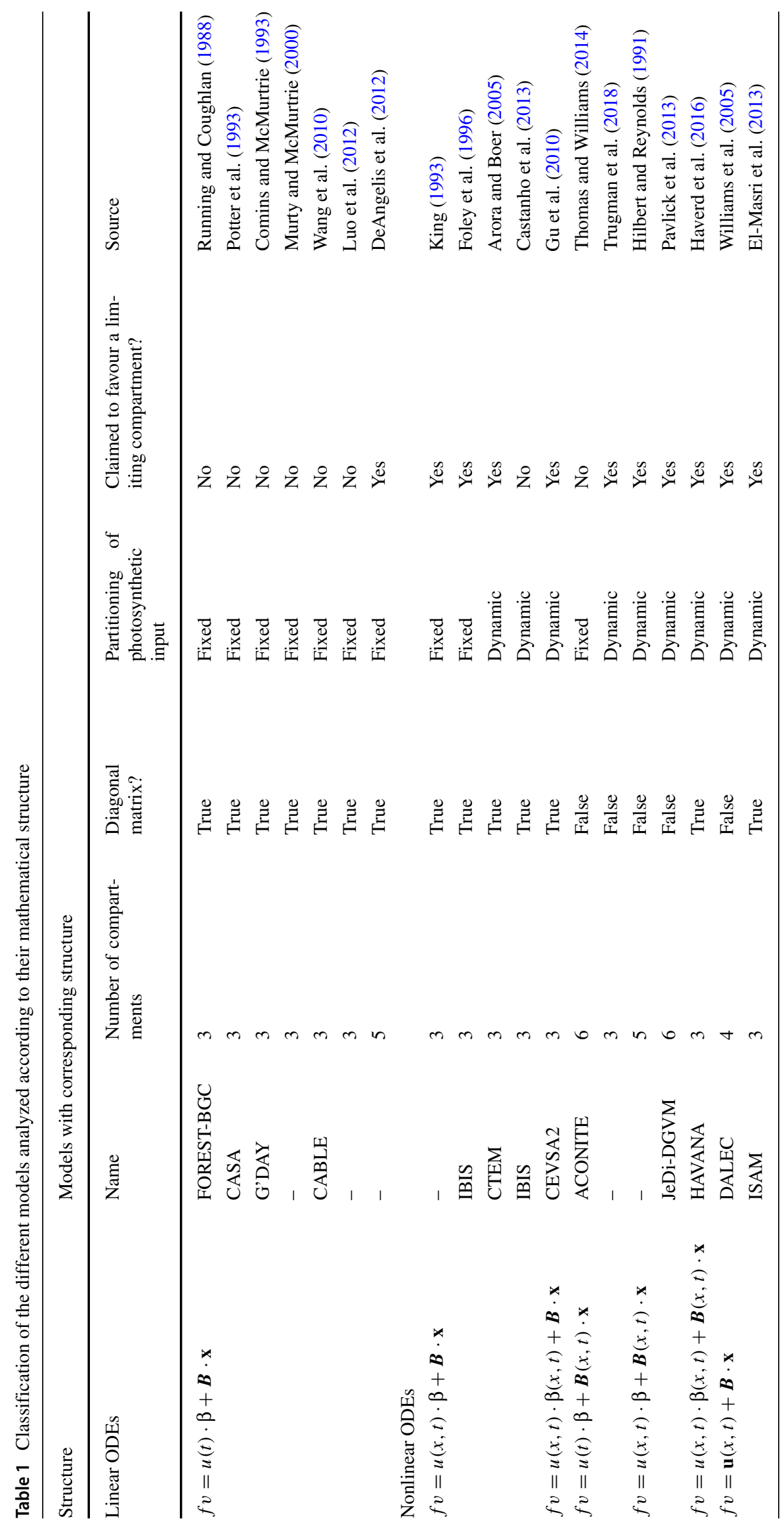


Table 2 Classification of the carbon allocation (CA) module of different models according to the main conceptual and mathematical approach used

\begin{tabular}{lll}
\hline Modelling approach & Mathematical formulation & Conceptual design of C partitioning \\
\hline Process based & Difference equations & Fixed coefficients \\
Individuals based & Linear ODEs & Dynamic \\
& Nonlinear ODEs & \\
\hline
\end{tabular}

ODEs, ordinary differential equations

In most PMDs, the environmental variables driving the models (e.g. temperature, water and nutrient content, light availability) were found in the equations that compute the photosynthetic input $(u)$, but sometimes air temperature and atmospheric $\mathrm{CO}_{2}$ concentration were implicitly included in environmental scalars that modify cycling rates. In addition, the photosynthetic input generally does not depend directly on the $\mathrm{C}$ content of the leaves (one of the state variables), rather on the leaf area index (LAI), which is not expressed in terms of leaf $\mathrm{C}$.

In contrast to the input dependency on environmental cues, the $\mathrm{C}$ transfers that shape the compartments via partitioning $(\beta)$ of photosynthetic input and $\mathrm{C}$ cycling $(\boldsymbol{B})$ are seldom driven by climate. In some cases, the partitioning is constrained by the ratio between some compartments (e.g. C foliage : C roots), but the most common constraint is the use of fixed coefficients that should sum up to 1 (see Table 1). One example is the model by King (1993), which was designed to analyze the influence of partitioning to root and foliage on forest production. This model has a structure in which the partitioning $(\beta)$ and the cycling $(\boldsymbol{B})$ contain parameters, instead of state variables or time-dependent variables. Thus, its partitioning scheme is independent of changes in the environment. In other schemes, the partitioning can switch between fixed and dynamic, depending on the sensitivity to changes in resource availability (e.g. the model CEVSA2 by Gu et al. (2010)).

Some PMDs have an intricate $\mathrm{C}$ cycling dynamic; for example, the model proposed by Hilbert and Reynolds (1991) has a structure inspired by the hypothesis of balanced root and shoot activity (Davidson 1969) and the response of specific shoot activity to resource availability. This model has five state variables: mass of leaf proteins, leaf structural components, roots, substrate carbon, and substrate nitrogen. The photosynthetic carbon is produced in the substrate compartments, and from there it is cycled to the other compartments. In cases like this, where all the photosynthetically fixed $\mathrm{C}$ is first stored in a compartment, there is no partitioning to multiple compartments, e.g. $\beta=$ $[1,0,0,0]$. Conversely, the $\boldsymbol{B}$ matrix is highly nonlinear because the $\mathrm{C}$ cycling depends on the state variables. This is why we broadened the mathematical framework and propose a new one that can accommodate nonlinearities.

\section{The new mathematical framework}

Based on the three categories in Table 2 and the fact that Eq. 2 can have particular cases based on the dependencies of its terms, we propose a new mathematical framework to study CA representations in models (Fig.3). This new framework takes into account that the mathematical abstraction from Fig. 2 may vary among models, depending on how their variables and parameters interact with each other, i.e. whether they depend on each other or not. These dependencies also have informative ecological implications such as positive feedback loops in the scalar function of system input $u$, or sink-dependent fluxes of the cycling matrix $\boldsymbol{B}$ (see Figs. 2 and 3), as those represented with the nonlinear model in the next section. These dependencies ultimately determine whether a model is linear or nonlinear. Nonlinear models have fluxes that depend on interactions between the state variables (symbolized with products and powers). This entails that the models have nondiagonal compartmental matrices where the off-diagonal values of the matrix also have state variables because the $\mathrm{C}$ transfer rates depend on them. In these kind of models, the compartments exchange $\mathrm{C}$, so it is also likely that they have at least one nonstructural $\mathrm{C}$ compartment that can act as an intermediary in the $\mathrm{C}$ exchange.

We classified the 19 PMDs according to their mathematical formulation-structure (see Table 1). The analysis behind this classification can be found on the reports generated for each of the PMDs using the bgc-md package (see the website). Notice that not all models have separated photosynthetic input $u$ and partitioning $\beta$. Particularly, the models with a partitioning scheme that depend on phenology often formulate this dependency as a set of if statements or piecewise functions. Thus, the $u$ and $\beta$ fuse together into the vector of photosynthetic inputs to each compartment $\mathbf{u}$, e.g. DALEC (Williams et al. 2005) and ISAM (El-Masri et al. 2013) (see Table 1). Another model with a partitioning scheme that depends on phenology according to its description is CASTANEA (Dufrene et al. 2005), but this 


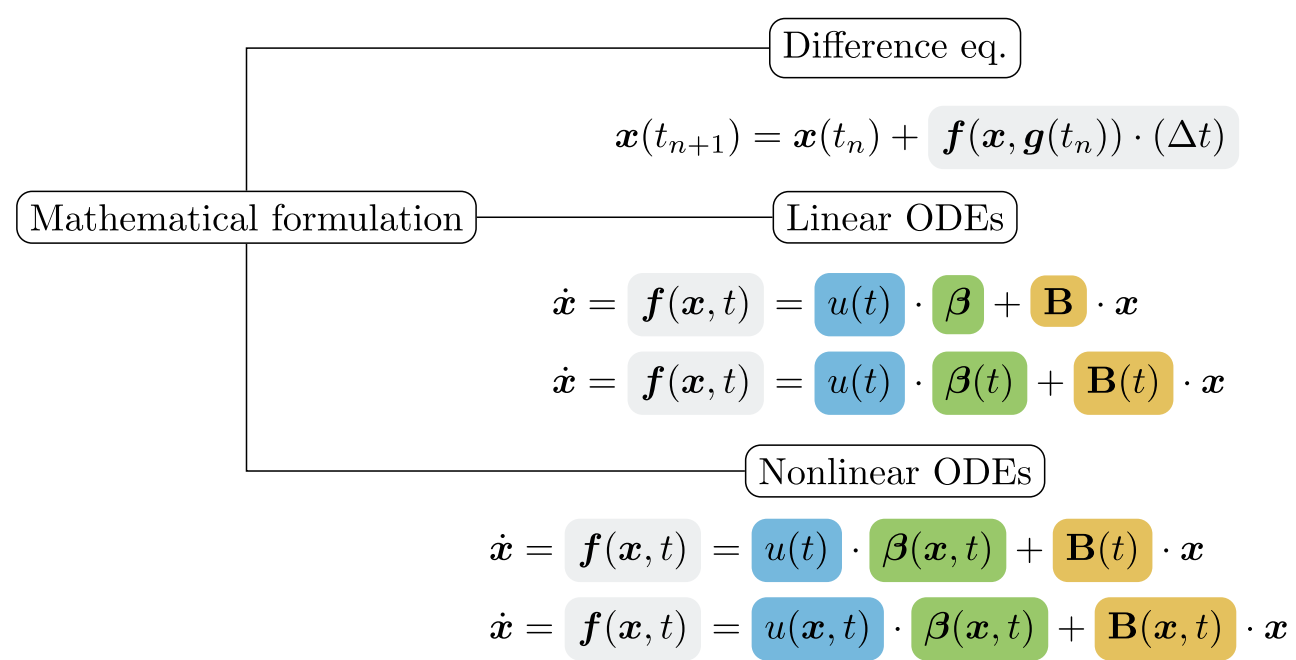

Fig. 3 Model classification according to their mathematical formulation, where $\mathbf{x}\left(t_{n+1}\right)$ is a vector of states for vegetation at time $t_{n+1}$. $f\left(\mathbf{x}, \mathbf{g}\left(t_{n}\right)\right)$ represents the dependency of the function valued vector $f$ on state variables $(\mathbf{x})$ and time-dependent functions $\left(\mathbf{g}\left(t_{n}\right)\right)$; it can also depend on state variables and time: $f(\mathbf{x}, t)$. The time step size

publication could not be included in the database because of the lack of equations.

\section{Implications of nonlinearities using an example of a vegetation system}

Nonlinearities can have a major impact on the model dynamics, when compared with a linear model with the same number of compartments and connections among them. We can illustrate this using a couple of models represented with the following sets of ordinary differential equations:

- A linear system:

$$
\begin{aligned}
& \dot{C} \mathrm{NSC}=C_{\mathrm{NSC}} \cdot\left(-\eta_{r}-\eta_{w}-\gamma_{f \mathrm{NSC}}\right)+C_{f} \cdot \eta_{\mathrm{NSC}} \\
& \dot{C_{f}}=C_{\mathrm{NSC}} \cdot \gamma_{f \mathrm{NSC}}+C_{f} \cdot\left(-\eta_{\mathrm{NSC}}-\gamma_{f}\right)+\eta_{f} \cdot k_{1} \\
& \dot{C_{w}}=C_{\mathrm{NSC}} \cdot \eta_{w}-C_{w} \cdot \gamma_{w} \\
& \dot{C_{r}}=C_{\mathrm{NSC}} \cdot \eta_{r}-C_{r} \cdot \gamma_{r}
\end{aligned}
$$

- And a nonlinear system:

$$
\begin{aligned}
C_{\mathrm{NSC}}= & C_{\mathrm{NSC}} \cdot\left(-\eta_{r}-\eta_{w}-\left(v_{2} /\left(C_{f}+k_{2}\right)\right)\right)+C_{f} \cdot \eta_{\mathrm{NSC}} \\
\dot{C}_{f}= & \left(C_{\mathrm{NSC}} \cdot v_{2} /\left(C_{f}+k_{2}\right)\right)+\left(C_{f} \cdot k_{1} \cdot v_{1} /\left(C_{\mathrm{NSC}}+k_{1}\right)\right) \\
& +C_{f} \cdot\left(-\eta_{\mathrm{NSC}}-\gamma_{f}\right) \\
\dot{C_{w}}= & C_{\mathrm{NSC}} \cdot \eta_{w}-C_{w} \cdot \gamma_{w} \\
\dot{C}_{r}= & C_{\mathrm{NSC}} \cdot \eta_{r}-C_{r} \cdot \gamma_{r}
\end{aligned}
$$

where, $\dot{C}$ is the changing amount of carbon in foliage $(f)$, nonstructural carbohydrates (NSC), wood $(w)$, and roots $(r)$, with respect to time; $k_{1}, k_{2}, v_{1}$, and $v_{2}$ are Michaelis-Menten parameters; $\eta_{f}$ is the flux rate of photosynthetically fixed $\mathrm{C}$ to foliage; $\eta_{\mathrm{NSC}}$ is the flux is $\Delta t=t_{n+1}-t_{n}$. The dependency of $u$ in time and state variables is represented by $u(\mathbf{x}, t)$. $\beta(t)$ : partitioning function valued vector that represents the time dependency of $\beta$, which may also depend on vegetation compartments (allowing for nonlinearities): $(\beta(\mathbf{x}, t)) . \boldsymbol{B}(t)$ represents the time dependency of $\boldsymbol{B}$

rate of $\mathrm{C}$ from foliage to $\mathrm{NSC} ; \eta_{w}$ is the flux rate of $\mathrm{C}$ from NSC to wood; $\eta_{r}$ is the flux rate of $\mathrm{C}$ from NSC to roots; $\gamma_{f, \mathrm{NSC}}$ is the flux rate of $\mathrm{C}$ from NSC to foliage; $\gamma_{f \mathrm{NSC}}$ is the flux rate of carbon from $C_{\mathrm{NSC}}$ to foliage; $\gamma_{f, w, r}$ is the rate at which $\mathrm{C}$ leaves each compartment (e.g. respiration, litter). The differences between them are highlighted in Table 3.

Both are autonomous systems (they are not driven by external variables such as temperature), where vegetation is divided into four compartments: nonstructural C (NSC), foliage, wood, and roots. The nonlinear model proposed here has a positive feedback loop that assures the increase in photosynthesis with an increase in foliage mass. This is represented with the nonlinear interaction between the foliage-dependent photosynthetic input and the dynamic partitioning: $u(x, t) \cdot b(x, t)$ (see Table 3 ).

These models were compared in terms of their stability, since this is one of the system properties that can be predicted from model structure. The calculations for this comparison can be found in the supplementary material: Supplement.ipynb. We found the fixed points, which are points where the $\mathrm{C}$ input and output of each compartment cancel out; in other words, we computed the analytical solution of the systems in steady state. Since the nonstructural $\mathrm{C}\left(C_{\mathrm{NSC}}\right)$ was the only compartment that exchanged material with all the others, we followed the following procedure: First, we set the right-hand side of the ordinary differential equations for all variables except $C_{\text {NSC }}$ (Eqs. 8-10 for the nonlinear model) to 0 . Then, we solved them for each state variable so that the solutions were in terms of $C_{\mathrm{NSC}}$. This reduced the dimensionality of 
Table 3 Sets of equations of the models from the example

\begin{tabular}{lll}
\hline Type of model & Linear & Nonlinear \\
\hline Matrix representation & $f=u \cdot \beta+\boldsymbol{B} \cdot \mathbf{x}$ & $f=u(x) \cdot \beta(x)+\boldsymbol{B}(x) \cdot \mathbf{x}$ \\
ODEs & $\dot{C}_{f}=u \cdot \eta_{f}+\gamma_{f, \mathrm{NSC}} \cdot C_{\mathrm{NSC}}-\left(\eta_{\mathrm{NSC}}+\gamma_{f}\right) \cdot C_{f}$ & $u=k_{1} \cdot C_{f}$ \\
& $\dot{C}_{\mathrm{NSC}}=\eta_{\mathrm{NSC}} \cdot C_{f}-\left(\eta_{r}+\eta_{w}+\gamma_{f, \mathrm{NSC}}\right) \cdot C_{\mathrm{NSC}}$ & $\eta_{f}=v 1 \cdot\left(k 1+C_{\mathrm{NSC}}\right)^{-1}$ \\
& $\dot{C}_{w}=\eta_{w} \cdot C_{\mathrm{NSC}}-\gamma_{w} \cdot C_{w}$ & $\gamma_{f, \mathrm{NSC}}=v 2 \cdot\left(k 2+C_{f}\right)^{-1}$ \\
& $\dot{C}_{r}=\eta_{r} \cdot C_{\mathrm{NSC}}-\gamma_{r} \cdot C_{r}$ & \\
\hline
\end{tabular}

Both models have the same sets of ordinary differential equations (ODEs), but the nonlinear has replaced some parameters for functions (right column). $\dot{C}$ : changing amount of carbon in foliage $(f)$, nonstructural carbohydrates $\left.{ }_{N S C}\right)$, wood $(w)$, and roots $(r)$, with respect to time; $u$ : photosynthetic input; $k_{1}$ : absorption rate; $k 1, k 2, v 1$, and $v 2$ : Michaelis-Menten parameters; $\eta_{f}$ : flux rate of photosynthetically fixed $\mathrm{C}$ to foliage; $\eta_{\mathrm{NSC}}$ : flux rate of C from foliage to NSC; $\eta_{w}$ : flux rate of C from NSC to wood; $\eta_{r}$ : flux rate of C from NSC to roots; $\gamma_{f, \mathrm{NSC}}$ : flux rate of C from NSC to foliage; $\gamma_{f, w, r}$ : rate at which $\mathrm{C}$ leaves each compartment (e.g. respiration, litter)

our system from four to one dimensions. We replaced the state variables in the Eq. 7 with these solutions, which could then be solved, i.e. we found the solution of $C_{\mathrm{NSC}}$ in steady state (Eq. $7=0$ ). This solution was then computed into the remaining ODEs to find the solutions of the other state variables in steady state.

For the linear input, we found a single fixed point: [ $\left.C_{\mathrm{NSC}}: 156.86, C_{f}: 137.25, C_{w}: 1568.63, C_{r}: 941.18\right]$. This goes in line with what is expected for autonomous linear models with constant input, which according to Strogatz (1994) can only have one fixed point. In contrast, the intricate nonlinear interactions between the foliage and NSC compartments had consequences for the predicted fixed points. We found a couple of potential fixed points for the nonlinear model: [0, 0, 0, 0, 0] (empty system), and $\left[C_{\mathrm{NSC}}: 286.70, C_{f}: 293.80, C_{w}: 2867.00, C_{r}:\right.$ 1720.20]. The fixed point where all $C$ stocks are 0 can only occur when the $\mathrm{C}$ input depends on a state variable, in this case the amount of carbon in the foliage $\left(C_{f}\right)$. Thus, since these models are mass-balanced, if $C_{f}$ reaches 0 , no photosynthetic input can be generated and all compartments will decay until no $\mathrm{C}$ remains in them. Note also that since the steady-state solution for the Eq. 7 has a higher order than 1 (see supplement), the model may have more than these two fixed points, which means that there could be potential bifurcations or tipping points. For more information on this topic, please refer to (Strogatz 2014, p. 52).

\section{Discussion}

Dynamic vegetation models have been a powerful tool for enhancing our understanding of the dynamics of carbon allocation in vegetation, but their representation of this process often differs, and these differences impact the model performance (Walker et al. 2015). Considering that modeldata synthesis projects have shown that model uncertainty can be reduced by identifying and evaluating the main assumptions causing differences among models (Medlyn et al. 2015), and that these assumptions are represented with different mathematical formulations, we performed a detailed analysis of the mathematical representation of the CA component of a representative sample of ecosystem models. This resulted in the identification of common structures from which we propose some generalizations. With this, we were able to obtain a deep insight into the properties of a system by identifying the factors on which photosynthesis and $\mathrm{C}$ partitioning and cycling depend on. This assessment motivated the formulation of the new mathematical framework proposed here, which emerges as a powerful tool to study carbon allocation in models.

This analysis brought to our attention that some carbon allocation models overlook properties that could be key to answer certain biological questions. For example, in most of the reviewed models, the photosynthetically fixed carbon is partitioned between compartments following predetermined coefficients or fractions (fixed partitioning scheme). Evidently, models with fixed coefficients for $\mathrm{C}$ partitioning and cycling would fail to simulate a vegetation that responds to environmental cues by adjusting its partitioning scheme: How can such a model be used to simulate the prioritization of a particular compartment when the environmental conditions change? Indeed, the compartments in models with fixed partitioning coefficients will always receive the same proportion of the photosynthetic input (independently from environmental cues), which means that these models may not be able to simulate observations such as the prioritization of the canopy of tropical forests a year after drought (Doughty et al. 2015). This would be a job for models with dynamic partitioning schemes, since they have functions in their $\beta$ vector instead of coefficients, and these functions may consist of environmental variables (e.g. temperature, water availability) or state variables (i.e. amount of carbon in a given compartment at a given time) that regulate the amount of carbon partitioned to each compartment (Guillemot et al. 2015). However, it should be recognized that 
models with fixed coefficients are easier to implement and run, which is perhaps the reason why this strategy is often used in global vegetation models. In contrast, some models used for simulations in smaller scales (in more detail) often have dynamic partitioning of the photosynthetic input. Therefore, knowing the implications and advantages of each scheme can further help in the selection of model properties that can better represent the response mechanisms inferred from observations or boost the improvement of current models.

Another model simplification that could be problematic in certain contexts was the lack of carbon exchange between the vegetation compartments, which goes in hand with the absence of storage and labile compartments. Although this exclusion may have been rooted on the assumption that nonstructural or labile carbon is an overflow compartment, studies have discredited this assumption showing that its role is more important than that (Richardson et al. 2013; Dietze et al. 2014; Doughty et al. 2015; Hartmann et al. 2015; Martínez-Vilalta et al. 2016; Muhr et al. 2016). In fact, there is an interesting source-sink relationship between the vegetation $\mathrm{C}$ compartments and the labile $\mathrm{C}$, and we speculate that this may have important implications in phenology (seasonal variability) in deciduous forests; the stored $\mathrm{C}$ can be cycled to the other compartments when the growing season starts, thus explaining the rapid loss and replenishment of carbon in foliage (Trumbore et al. 2015). Indeed, a study of climate sensitivity of NPP simulated by two dynamic global vegetation models concluded that these models could be improved with a more detailed representation of carbon reserves (Zhang et al. 2017). Although this dynamic has been represented in earlier individual-based models (Iwasa and Cohen 1989), this C exchange that results from phenology and storage was rarely observed within the structures of large-scale models. Thus, the phenology in such models might need to be represented with alternative strategies (e.g. hard coded rules) or might be left out completely, with the consequences that this may have for predicted carbon dynamics from season to season.

One of the characteristics that most of the reviewed models share is that they are linear; the carbon processes are expressed as the sum of the $\mathrm{C}$ fixed in the compartments and the one leaving the compartments-terms 1 and 2 of the first row in Eq. 1, respectively. This linear structure ignores possible nonlinear interactions among vegetation processes that can arise (e.g. when partitioning depends on state variables $\beta(\mathbf{x}, t)$ ). Even though the linearity of some models is a simplification used to increase the speed of model runs without jeopardizing the trends at global scales, this characteristic could result in simulation errors when the aim is to model finer spatio-temporal scales (Merganičová et al. 2019). Most importantly, this simplification could be the reason why some models fail to capture the response of vegetation to extreme climatic changes; empirical findings suggest that climate change alone has contrasting effects on vegetation, and the effects of multiple driving factors on vegetation is not always additive (Leuzinger et al. 2011; Dieleman et al. 2012).

Categorizing models of interest in this framework has several advantages (as described above and in the following section), but a categorization performed solely based on the published model descriptions (PMDs) might not be advisable because they leave out important details. The PMDs of complex models such as the Dynamic Vegetation Models (DGVMs) often lack complete sets of equations, parameter values, or they do not describe the way in which the time steps are advanced when difference equations are used (e.g. LPJ by Sitch et al. (2003) and O-CN by Zaehle and Friend (2010)). Given that these details not only guarantee the reproducibility of the results, but the reliability of the model categorization within this framework, the source code of these models also needs to be assessed. As challenging as that process may be, the development of such models within this framework can be an efficient way to improve their performance and the one of the Earth system models to which they are coupled. Thus, we highly encourage other researchers to contribute with their own models to this database.

Individual-based models (e.g. aDGVM by Scheiter and Higgins (2009) and the single plant-based model proposed by Iwasa and Cohen (1989)) were not included in our review because interactions among many individuals are challenging to write analytically. However, we can think about these interactions as functions or maps that quantify the amount of carbon that is allocated to plant compartments or are transferred from one compartment to another. Solving individual-based models numerically and aggregating the results in plant compartments would allow one to write the matrices and vectors we propose. They would change over time due to all processes included in the original model, but we can recover these dynamics in an aggregated form. This strategy of capturing complex nonlinear interactions to reconstruct a compartmental system has been recently described in Metzler et al. (2018).

\section{Implications and future studies}

We have identified some of the impacts that certain model structures used to represent $\mathrm{CA}$ have on the qualitative behaviour of simulations, in agreement with other systematic studies (Holling 1973; Jacquez and Simon 1993; Strogatz 1994). This leads us to another of the main contributions of this framework, which is the ease to identify models that fall into the Compartmental Systems category. 
Compartmental systems are those whose compartments exchange material, and according to the qualitative theory proposed by Jacquez and Simon (1993), their structure may have important implications in the stability of the system. This was one of the main motivations for focusing this study in models where the vegetation is arbitrarily divided into compartments delimited by artificial boundaries, in spite of the fact that this delimitation does not exist in nature (Fox 1992b).

A stability analysis can inform us, for example, whether the modelled system could potentially reach a steady state, i.e. if each state variable in the model can converge to a fixed point in time, when its inputs and outputs are cancelled out. Note that systems with time-dependent variables such as $f(\mathbf{x}, t)=u(\mathbf{x}, t) \cdot \beta(\mathbf{x}, t)+\boldsymbol{B}(\mathbf{x}, t) \cdot \mathbf{x}$ are classified by this theory as nonautonomous systems and do not converge to a steady state (see stability of nonautonomous systems in Jacquez and Simon (1993)). This is an interesting property because, even though it is highly debated whether the ecosystems can reach such a steady state, it is an assumption that has to be done in order to use some methods to diagnose the model performance (e.g. mean age of carbon) (Sierra et al. 2016).

Given that the structure of the models determines the dynamics that can be simulated (Holling 1973; Strogatz 1994), the modelled response of vegetation to changing climatic conditions depends on the variables and parameters used, as well as on their interactions, i.e. whether the systems are linear or not. Evidently, finding the right combination remains the most challenging part, because several aspects of the potential capability of vegetation to exploit climatic conditions remain unclear. Nonetheless, these and other interesting dynamics could be explored using models, and the software implemented in the database can help to test different hypothesis and parameter values to improve model performance. These improved models can then be used to guide field experiments (e.g. De Kauwe et al. 2017) by providing a priori predictions of the ecosystem response to treatments (Medlyn et al. 2016).

Perhaps one of the most important features of this framework is the division of the carbon allocation process into components of biogeochemical relevance (input: $u$, partitioning: $\beta$, and cycling: $\boldsymbol{B}$ ); i.e. the complex conceptual design used in some models to represent the entire carbon allocation process in vegetation is arranged into smaller objects of interest that can be individually explored in detail. This is specially relevant for studies that aim at punctual aspects of the global carbon cycle as it is commonly done in empirical studies such as the study performed by Malhi et al. (2015), where they assessed the linkages between photosynthesis, productivity, growth, and biomass in lowland Amazonian forests using the largest data set assembled to that date. These empirical studies are crucial when trying to constrain terrestrial carbon cycle projections (Mystakidis et al. 2016), but it is important to know how to interpret the observation-based carbon flux estimates and incorporate them into models whose structure are a reflection of the observed carbon allocation strategies. Thus, this work could lead to a close dialog between empirical and theoretical research fields that could result in interesting findings.

\section{Conclusions}

Carbon allocation in vegetation is a complex process that involves $\mathrm{C}$ flowing into, between and out of plant compartments, at different rates. This concept can be generalized and formalized using the mathematical concept of compartmental dynamical systems, which is the backbone of the mathematical framework proposed here as means to provide an optimal common ground for the comparison of model structures. Essentially, with this matrix representation, important interactions within the elements of the model become conspicuous, e.g. nonlinear interactions among state variables and model dependencies on variables whose value can change with time. In this way, it facilitates the classification of models depending on their autonomy, i.e. nonautonomous models are driven by external variables that depend on time, whereas autonomous models do not, and according to their linearity, i.e. as linear and nonlinear models. Here, we found that many vegetation models can be represented in matrix form as a nonautonomous compartmental system of nonlinear ODEs. However, many models, particularly those used for large-scale simulations, use a linear representation with no interactions among ecosystem compartments.

We also identified some general properties of models according to the linearity and autonomy of the systems. We found that, although the linear structure is common, other structures with nonlinearities have been also proposed. These nonlinearities can be accommodated in the new mathematical framework proposed here. This framework has allowed us to assess models in a simple way and can be a powerful aid in the interaction between theoretical and empirical research in ecosystem ecology and other related fields. It is an interface that summarizes the models' perspective of carbon allocation and highlights relations (dependencies) between factors that are normally studied separately and in detail in the field and the lab; so, hopefully both could find a common language to share their knowledge. This conceptual/mathematical framework may allow us to find new insights into the study of the global carbon cycle under changing climate and disturbance regimes, and identify gaps where more experiments and theoretical work is needed. 
Acknowledgements The authors would like to thank Henrik Hartmann and Volker Grimm for their valuable comments on earlier versions of this manuscript.

Author contributions All authors contributed with the design of this work, mainly Carlos A. Sierra, who also revised the manuscript. Verónika Ceballos-Núñez performed the research and wrote the manuscript. Markus Müller contributed to the code implementation.

Funding information Open access funding provided by Projekt DEAL. This research was funded by the Max Planck Society and the German Research Foundation through its Emmy Noether Program (SI 1953/2-1)

\section{Compliance with ethical standards}

Competing interests The authors declare that they have no conflict of interest.

Open Access This article is licensed under a Creative Commons Attribution 4.0 International License, which permits use, sharing, adaptation, distribution and reproduction in any medium or format, as long as you give appropriate credit to the original author(s) and the source, provide a link to the Creative Commons licence, and indicate if changes were made. The images or other third party material in this article are included in the article's Creative Commons licence, unless indicated otherwise in a credit line to the material. If material is not included in the article's Creative Commons licence and your intended use is not permitted by statutory regulation or exceeds the permitted use, you will need to obtain permission directly from the copyright holder. To view a copy of this licence, visit http:// creativecommonshorg/licenses/by/4.0/.

\section{References}

Anderson DH (1983) Compartmental modeling and tracer kinetics, vol 50. Springer Science \& Business Media

Arora VK, Boer GJ (2005) A parameterization of leaf phenology for the terrestrial ecosystem component of climate models. Glob Chang Biol 11(1):39-59. https://doi.org/10.1111/j.1365-2486. 2004.00890.x

Canadell JG, Le Quéré C, Raupach MR, Field CB, Buitenhuis ET, Ciais P, Conway TJ, Gillett NP, Houghton RA, Marland G (2007) Contributions to accelerating atmospheric $\mathrm{CO}_{2}$ growth from economic activity, carbon intensity, and efficiency of natural sinks. Proc Natl Acad Sci 104(47):18866-18870

Castanho ADA, Coe MT, Costa MH, Malhi Y, Galbraith D, Quesada CA (2013) Improving simulated amazon forest biomass and productivity by including spatial variation in biophysical parameters. Biogeosciences 10(4):2255-2272. https://doi.org/10.5194/bg-102255-2013

Chen JL, Reynolds J (1997) Gepsi: A generic plant simulator based on object-oriented principles. Ecol Model 94(1):53-66. https://doi.org/10.1016/S0304-3800(96)01928-X, http://tinyurl. sfx.mpg.de/uaki

Comins HN, McMurtrie RE (1993) Long-term response of nutrientlimited forests to $\mathrm{CO}_{2}$ enrichment; equilibrium behavior of plantsoil models. Ecol Appl 3(4):666-681

Davidson RL (1969) Effect of root/leaf temperature differentials on root/shoot ratios in some pasture grasses and clover. Ann Bot 33(3):561-569. https://doi.org/10.1093/oxfordjournals.aob. a084308
De Kauwe MG, Medlyn BE, Zaehle S, Walker AP, Dietze MC, Wang YP, Luo Y, Jain AK, El-Masri B, Hickler T, Wårlind D, Weng E, Parton WJ, Thornton PE, Wang S, Prentice IC, Asao S, Smith B, McCarthy HR, Iversen CM, Hanson PJ, Warren JM, Oren R, Norby RJ (2014) Where does the carbon go? A model-data intercomparison of vegetation carbon allocation and turnover processes at two temperate forest freeair $\mathrm{CO}_{2}$, enrichment sites. New Phytologist 203(3):883-899. https://doi.org/10.1111/nph.12847

De Kauwe MG, Medlyn BE, Walker AP, Zaehle S, Asao S, Guenet $\mathrm{B}$, Harper AB, Hickler T, Jain AK, Luo Y, Lu X, Luus K, Parton WJ, Shu S, Wang YP, Werner C, Xia J, Pendall E, Morgan JA, Ryan EM, Carrillo Y, Dijkstra FA, Zelikova TJ, Norby RJ (2017) Challenging terrestrial biosphere models with data from the long-term multifactor Prairie Heating and $\mathrm{CO}_{2}$ Enrichment experiment. Glob Chang Biol 23(9):3623-3645. https://doi.org/10.1111/gcb.13643

DeAngelis DL, Ju S, Liu R, Bryant JP, Gourley SA (2012) Plant allocation of carbon to defense as a function of herbivory, light and nutrient availability. Theor Ecol 5(3):445-456. https://doi.org/10.1007/s12080-011-0135-z

Dieleman WIJ, Vicca S, Dijkstra FA, Hagedorn F, Hovenden MJ, Larsen KS, Morgan JA, Volder A, Beier C, Dukes JS, King J, Leuzinger S, Linder S, Luo Y, Oren R, De Angelis P, Tingey D, Hoosbeek MR, Janssens IA (2012) Simple additive effects are rare: a quantitative review of plant biomass and soil process responses to combined manipulations of $\mathrm{CO}_{2}$ and temperature. Glob Chang Biol 18(9):2681-2693

Dietze MC, Sala A, Carbone MS, CC I, Mantooth JA, Richardson AD, Vargas R (2014) Nonstructural carbon in woody plants. Annu Rev Plant Biol 65(1):667-687. https://doi.org/10.1146/annurev-arplant050213-040054

Doughty CE, Metcalfe DB, Girardin CA, Amézquita FF, Cabrera DG, Huasco WH, Silva-Espejo JE, Araujo-Murakami A, Da Costa MC, Rocha W, Feldpausch TR, Mendoza AL, Da Costa AC, Meir P, Phillips OL, Malhi Y (2015) Drought impact on forest carbon dynamics and fluxes in Amazonia. Nature 519(7541):7882. https://doi.org/10.1038/nature14213

Dufrene E, Davi H, Francois C, le Maire G, Dantec VL (2005) Modelling carbon and water cycles in a beech forest Part I: Model description and uncertainty analysis on modelled NEE. Ecol Model 185(2-4):407-436. https://doi.org/10.1016/j.ecolmodel. 2005.01.004, http://tinyurl.sfx.mpg.de/uajb

Eglin T, Francois C, Michelot A, Delpierre N, Damesin C (2010) Linking intra-seasonal variations in climate and tree-ring $\Delta^{13} \mathrm{C}$ : a functional modelling approach. Ecol Model 221(15):1779-1797. https://doi.org/10.1016/j.ecolmodel.2010.04.007, http://tinyurl. sfx.mpg.de/uai5

El-Masri B, Barman R, Meiyappan P, Song Y, Liang M (2013) Carbon dynamics in the amazonian basin: integration of eddy covariance and ecophysiological data with a land surface model. Agric For Meteorol 182(Sp. Iss. SI):156-167. https://doi.org/10.1016/j. agrformet.2013.03.011, http://tinyurl.sfx.mpg.de/uahl

Falster DS, Brännström ^̊, Westoby M, Dieckmann U (2017) Multitrait successional forest dynamics enable diverse competitive coexistence. Proc Natl Acad Sci 114(13):E2719-E2728. https://doi.org/10.1073/pnas.1610206114, https://www.pnas.org/ content/114/13/E2719

Fatichi S, Leuzinger S (2013) Reconciling observations with modeling: the fate of water and carbon allocation in a mature deciduous forest exposed to elevated $\mathrm{CO}_{2}$. Agric For Meteorol 174:144-157. https://doi.org/10.1016/j.agrformet.2013.02.005, http://tinyurl. sfx.mpg.de/uahp

Foley JA, Prentice IC, Ramankutty N, Lewis S, Pollard D, Sitch S, Haxeltine A (1996) An integrated biosphere model of land surface 
processes, terrestrial carbon balance, and vegetation dynamics. Glob Biogeochem Cycles 10(4):603-628. https://doi.org/10.1029/ 96GB02692

Fox G (1992a) The effect of time-varying mortality and carbon assimilation on models of carbon allocation in annual plants. Evol Ecol 6(6):500-518. https://doi.org/10.1007/BF02270694, http:// tinyurl.sfx.mpg.de/uak4

Fox GA (1992b) Annual plant life histories and the paradigm of resource allocation. Evol Ecol 6(6):482-499. https://doi.org/10. 1007/BF02270693

Franklin O, Johansson J, Dewar RC, Dieckmann U, McMurtrie RE, Brännström A, Dybzinski R (2012) Modeling carbon allocation in trees: a search for principles. Tree Physiol 32(6):648-666. https://doi.org/10.1093/treephys/tpr138

Friedlingstein P, Cox P, Betts R, Bopp L, Von Bloh W, Brovkin V, Cadule P, Doney S, Eby M, Fung I, Bala G, John J, Jones C, Joos F, Kato T, Kawamiya M, Knorr W, Lindsay K, Matthews HD, Raddatz T, Rayner P, Reick C, Roeckner E, Schnitzler KG, Schnur R, Strassmann K, Weaver AJ, Yoshikawa C, Zeng N (2006) Climate-carbon cycle feedback analysis: results from the c4MIP model intercomparison. J Clim 19(14):3337-3353

Friedlingstein P, Meinshausen M, Arora VK, Jones CD, Anav A, Liddicoat SK, Knutti R (2014) Uncertainties in CMIP5 climate projections due to carbon cycle feedbacks. J Clim 27(2):511-526. https://doi.org/10.1175/JCLI-D-12-00579.1

Govingjee (2009) Photosynthesis in silico. Understanding complexity from molecules to ecosystems, vol 29. Springer

Grimm V, Berger U, Bastiansen F, Eliassen S, Ginot V, Giske J, Goss-Custard J, Grand T, Heinz S, Huse G, Huth A, Jepsen J, Jørgensen C, Mooij W, Müller B, Pe'er G, Piou CF, Railsback SM, Robbins A, Deangelis D (2006) A standard protocol for describing individual-based and agent based models. Ecol Model 198:115-126

Grimm V, Berger U, Deangelis D, Polhill J, Giske J, F Railsback S (2010) The ODD protocol: a review and first update. Ecol Model 221:2760-2768

Gu F, Zhang Y, Tao B, Wang Q, Yu G (2010) Modeling the effects of nitrogen deposition on carbon budget in two temperate forests. Ecol Complex 7(2, Sp. Iss. SI):139148. https://doi.org/10.1016/j.ecocom.2010.04.002, http://tinyurl. sfx.mpg.de/uaig

Guillemot J, Martin-StPaul NK, Dufrêne E, François C, Soudani K, Ourcival JM, Delpierre N (2015) The dynamic of the annual carbon allocation to wood in european tree species is consistent with a combined source-sink limitation of growth: implications for modelling. Biogeosciences 12(9):27732790. https://doi.org/10.5194/bg-12-2773-2015, https://www. biogeosciences.net/12/2773/2015/

Hartmann H, Trumbore S (2016) Understanding the roles of nonstructural carbohydrates in forest trees -from what we can measure to what we want to know. New Phytol 211(2):386-403. https://doi.org/10.1111/nph.13955

Hartmann H, McDowell NG, Trumbore S (2015) Allocation to carbon storage pools in Norway spruce saplings under drought and low $\mathrm{CO}_{2}$. Tree Physiol 35(3):243-252. https://doi.org/10.1093/treephys/tpv019

Hartmann H, Adams HD, Hammond WM, Hoch G, Landhäusser SM, Wiley E, Zaehle S (2018) Identifying differences in carbohydrate dynamics of seedlings and mature trees to improve carbon allocation in models for trees and forests. Environ Exp Bot 152:718. https://doi.org/10.1016/j.envexpbot.2018.03.011, http://www. sciencedirect.com/science/article/pii/S0098847218303915
Haverd V, Smith B, Raupach M, Briggs P, Nieradzik L, Beringer J, Hutley L, Trudinger CM, Cleverly J (2016) Coupling carbon allocation with leaf and root phenology predicts tree-grass partitioning along a savanna rainfall gradient. Biogeosciences 13(3):761-779. https://doi.org/10.5194/bg-13-761-2016, https:// www.biogeosciences.net/13/761/2016/

Hilbert DW, Reynolds JF (1991) A model allocating growth among leaf proteins, shoot structure, and root biomass to produce balanced activity. Ann Bot 68(5):417-425

Hofhansl F, Schnecker J, Singer G, Wanek W (2014) New insights into mechanisms driving carbon allocation in tropical forests. New Phytol 205, https://doi.org/10.1111/nph.13007

Holling CS (1973) Resilience and stability of ecological systems. Annu Rev Ecol Syst 4:1-23

Huntingford C, Cox PM, Lenton TM (2000) Contrasting responses of a simple terrestrial ecosystem model to global change. Ecol Model 134(1):41-58. https://doi.org/10.1016/S0304-3800(00)00330-6, http://tinyurl.sfx.mpg.de/uajw

Iwasa Y, Cohen D (1989) Optimal growth schedule of a perennial plant. Am Nat 133, https://doi.org/10.1086/284931

Jacquez JA, Simon CP (1993) Qualitative theory of compartmental systems. Siam Rev 35(1):43-79

King DA (1993) A model analysis of the influence of root and foliage allocation on forest production and competition between trees. Tree Physiol 12(2):119-135. https://doi.org/10.1093/treephys/12. 2.119

Körner C (2017) A matter of tree longevity. Science 355(6321):130 131. https://doi.org/10.1126/science.aal2449

Lacointe A (2000) Carbon allocation among tree organs: a review of basic processes and representation in functional-structural tree models. Annals of Forest Science 57(5-6):521-533. https://doi. org/10.1051/forest:2000139

Lazzarotto P, Calanca P, Fuhrer J (2009) Dynamics of grass-clover mixtures-an analysis of the response to management with the productive grassland simulator (prograss). Ecol Model 220(5):703724. https://doi.org/10.1016/j.ecolmodel.2008.11.023, http:// tinyurl.sfx.mpg.de/uaip

Leuzinger S, Luo Y, Beier C, Dieleman W, Vicca S, Koerner C (2011) Do global change experiments overestimate impacts on terrestrial ecosystems? Trends Ecol Evol 26(5):236-241

Li G, Harrison SP, Prentice IC, Falster D (2014) Simulation of tree-ring widths with a model for primary production, carbon allocation, and growth. Biogeosciences 11(23):67116724. https://doi.org/10.5194/bg-11-6711-2014, http://tinyurl.sfx. mpg.de/uahk

Litton CM, Raich JW, Ryan MG (2007) Carbon allocation in forest ecosystems. Glob Chang Biol 13(10):2089-2109

Luenberger DG, Hill RL (1979) Introduction to dynamic systems : theory, models and applications. Wiley, New York

Luo Y, White LW, Canadell JG, DeLucia EH, Ellsworth DS, Finzi A, Lichter J, Schlesinger WH (2003) Sustainability of terrestrial carbon sequestration: a case study in duke forest with inversion approach. Global Biogeochem Cycles 17(1):n/a-n/a. https://doi.org/10.1029/2002GB001923

Luo Y, Weng E, Yang Y (2012) Ecosystem ecology. In: Hastings A, Gross L (eds) Encyclopedia of theoretical ecology. University of California Press, Berkeley, pp 219-229

Malhi Y, Doughty CE, Goldsmith GR, Metcalfe DB, Girardin CAJ, Marthews TR, del Aguila-Pasquel J, Aragão LEOC, AraujoMurakami A, Brando P, da Costa ACL, Silva-Espejo JE, Farfán Amézquita F, Galbraith DR, Quesada CA, Rocha W, SalinasRevilla N, Silvério D, Meir P, Phillips OL (2015) The linkages 
between photosynthesis, productivity, growth and biomass in lowland amazonian forests. Glob Chang Biol 21(6):2283-2295. https://doi.org/10.1111/gcb.1285

Martínez-Vilalta J, Sala A, Asensio D, Galiano L, Hoch G, Palacio S, Piper FI, Lloret F (2016) Dynamics of non-structural carbohydrates in terrestrial plants: a global synthesis. Ecol Monogr 86(4):495-516. https://doi.org/10.1002/ecm.1231

Medlyn B, Zaehle S, De Kauwe M, Walker A, Dietze M, Hanson P, Hickler T, Jain A, Luo Y, Parton W, Prentice I, E Thornton P, Wang S, Wang Y, Weng E, Iversen C, Mccarthy H, Warren J, Oren R, Norby R (2015) Using ecosystem experiments to improve vegetation models. Nat Clim Chang 5:528-534. https://doi.org/10.1038/nclimate2621

Medlyn BE, De Kauwe MG, Zaehle S, Walker AP, Duursma RA, Luus K, Mishurov M, Pak B, Smith B, Wang YP, Yang X, Crous KY, Drake JE, Gimeno TE, Macdonald CA, Norby RJ, Power SA, Tjoelker MG, Ellsworth DS (2016) Using models to guide field experiments: a priori predictions for the $\mathrm{CO}_{2}$ response of a nutrient- and water-limited native Eucalypt woodland. Glob Chang Biol 22(8):2834-2851. https://doi.org/10.1111/gcb. 13268

Merganičová K, Merganič J, Lehtonen A, Vacchiano G, Sever MZO, Augustynczik ALD, Grote R, Kyselová I, Mäkelä A, Yousefpour R, Krejza J, Collalti A, Reyer CPO (2019) Forest carbon allocation modelling under climate change. Tree Physiol 39(12):1937-1960. https://doi.org/10.1093/treephys/tpz105

Metzler H, Müller M, Sierra C (2018) Transit-time and age distributions for nonlinear time-dependent compartmental systems. Proc Natl Acad Sci 115:201705296. https://doi.org/10.1073/pnas. 1705296115

Meurer A, Smith CP, Paprocki M, Čertík O, Kirpichev SB, Rocklin M, Kumar A, Ivanov S, Moore JK, Singh S, Rathnayake T, Vig S, Granger BE, Muller RP, Bonazzi F, Gupta H, Vats S, Johansson F, Pedregosa F, Curry MJ, Terrel AR, Roučka v SabooA, Fernando I, Kulal S, Cimrman R, Scopatz A (2017) Sympy: symbolic computing in python. PeerJ Comput Sci 3:e103. https://doi.org/10.7717/peerj-cs.103

Muhr J, Messier C, Delagrange S, Trumbore S, Xu X, Hartmann H (2016) How fresh is maple syrup? Sugar maple trees mobilize carbon stored several years previously during early springtime sapascent. New Phytol 209(4):1410-1416. https://doi.org/10.1111/ nph.13782

Murty D, McMurtrie R (2000) The decline of forest productivity as stands age: a model-based method for analysing causes for the decline. Ecol Model 134(2-3):185-205. https://doi.org/10.1016/ S0304-3800(00)00345-8, http://tinyurl.sfx.mpg.de/uaju

Mystakidis S, Davin EL, Gruber N, Seneviratne SI (2016) Constraining future terrestrial carbon cycle projections using observationbased water and carbon flux estimates. Glob Chang Biol 22(6):2198-2215. https://doi.org/10.1111/gcb.13217

Pavlick R, Drewry DT, Bohn K, Reu B, Kleidon A (2013) The Jena Diversity-Dynamic Global Vegetation Model (JeDiDGVM): a diverse approach to representing terrestrial biogeography and biogeochemistry based on plant functional tradeoffs . Biogeosciences 10(6):4137-4177. https://doi.org/10.5194/ bg-10-4137-2013, http://tinyurl.sfx.mpg.de/uahq

Potter CS, Randerson JT, Field CB, Matson PA, Vitousek PM, Mooney HA, Klooster SA (1993) Terrestrial ecosystem production: a process model based on global satellite and surface data. Glob Biogeochem Cycles 7(4):811-841. https://doi.org/10.1029/93GB 02725

Purves D, Pacala S (2008) Predictive models of forest dynamics. Science 320(5882):1452-1453. https://doi.org/10.1126/science. 1155359
Quaiser T, Dittrich A, Schaper F, Monnigmann M (2011) A simple work flow for biologically inspired model reductionapplication to early JAK-STAT signaling. BMC Syst Biol 5:30. https://doi.org/10.1186/1752-0509-5-30

Raue A, Kreutz C, Maiwald T, Bachmann J, Schilling M, Klingmüller U, Timmer J (2009) Structural and practical identifiability analysis of partially observed dynamical models by exploiting the profile likelihood. Bioinformatics 25(15):1923. https://doi.org/10.1093/bioinformatics/btp358

Reichstein M, Richardson AD, Migliavacca M, Carvalhais N (2014) Plant-environment interactions across multiple scales. In: Monson RK (ed) Ecology and the environment. Springer, New York, pp 1-27. https://doi.org/10.1007/978-1-4614-7501-9_22

Richardson AD, Carbone MS, Keenan TF, Czimczik CI, Hollinger DY, Murakami P, Schaberg PG, Xu X (2013) Seasonal dynamics and age of stemwood nonstructural carbohydrates in temperate forest trees. New Phytol 197(3):850-861. https://doi.org/10.1111/ nph. 12042

Running SW, Coughlan JC (1988) A general model of forest ecosystem processes for regional applications I. Hydrologic balance, canopy gas exchange and primary production processes. Ecol Model 42(2):125-154. https://doi.org/10.1016/0304-3800(88)90 112-3

Scheiter S, Higgins SI (2009) Impacts of climate change on the vegetation of Africa: an adaptive dynamic vegetation modelling approach. Glob Chang Biol 15(9):2224-2246. https://doi.org/10. 1111/j.1365-2486.2008.01838.x

Schiestl-Aalto P, Kulmala L, Mäkinen H, Nikinmaa E, Mäkelä A (2015) CASSIA - a dynamic model for predicting intra-annual sink demand and interannual growth variation in Scots pine. New Phytol 206(2):647-659. https://doi.org/10.1111/nph.13275

Schimel D, House JI, Hibbard K, Bousquet P, Ciais P, Peylin $\mathrm{P}$, Braswell BH, Apps MJ, Baker D, Bondeau A, Canadell J, Churkina G, Cramer W, Denning AS, Field CB, Friedlingstein P, Goodale CL, Heimann M, Houghton RA, Melillo JM, Moore IIIB, D M NobleI, Pacala S, Prentice IC, Raupach MR, Rayner PJ, Scholes R, Steffen W, Wirth C (2001) Recent patterns and mechanisms of carbon exchange by terrestrial ecosystems. Nature 414:169-172

Sierra CA, Müller M, Trumbore SE (2012) Models of soil organic matter decomposition: the SoilR package, version 1.0. Geosci Model Dev 5(4):1045-1060. https://doi.org/10.5194/gmd-5-1045-2012

Sierra CA, M“uller M, Metzler H, Manzoni S, Trumbore SE (2016) The muddle of ages, turnover, transit, and residence times in the carbon cycle. Global Change Biology in print. https://doi.org/10. $1111 / \mathrm{gcb} .13556$

Sitch S, Smith B, Prentice IC, Arneth A, Bondeau A, Cramer W, Kaplan JO, Levis S, Lucht W, Sykes MT, Thonicke K, Venevsky S (2003) Evaluation of ecosystem dynamics, plant geography and terrestrial carbon cycling in the LPJ dynamic global vegetation model. Glob Chang Biol 9(2):161-185. https://doi.org/10.1046/j.1365-2486.2003.00569.x

Soetaert K, Hoffmann M, Meire P, Starink M, van Oevelen D (2004) Modeling growth and carbon allocation in two reed beds (phragmites australis) in the scheldt estuary. Aquat Bot 79(3):211234. https://doi.org/10.1016/j.aquabot.2004.02.001, http://tinyurl. sfx.mpg.de/uajd

Strogatz S (2014) Nonlinear dynamics and chaos: with applications to physics, biology, chemistry, and engineering. Studies in nonlinearity, Westview Press, https://books.google.de/books? id=JDQGAwAAQBAJ

Strogatz SH (1994) Nonlinear dynamics and chaos: with applications to physics, biology, chemistry, and engineering. Perseus publishing 
Thomas RQ, Williams M (2014) A model using marginal efficiency of investment to analyze carbon and nitrogen interactions in terrestrial ecosystems (ACONITE version 1). Geosci Model Dev 7(5):2015-2037. https://doi.org/10.5194/gmd-7-20152014

Trugman AT, Detto M, Bartlett MK, Medvigy D, Anderegg WRL, Schwalm C, Schaffer B, Pacala SW (2018) Tree carbon allocation explains forest drought-kill and recovery patterns. Ecol Lett 21(10):1552-1560. https://doi.org/10.1111/ele.13136

Trugman AT, Anderegg LDL, Sperry JS, Wang Y, Venturas M, Anderegg WRL (2019) Leveraging plant hydraulics to yield predictive and dynamic plant leaf allocation in vegetation models with climate change. Glob Chang Biol 25(12):4008-4021. https://doi.org/10.1111/gcb.14814

Trumbore S, Czimczik CI, Sierra CA, Muhr J, Xu X (2015) Nonstructural carbon dynamics and allocation relate to growth rate and leaf habit in california oaks. Tree Physiol 35(11):1206. https://doi.org/10.1093/treephys/tpv097

Trumbore SE (2006) Carbon respired by terrestrial ecosystems recent progress and challenges. Glob Chang Biol 12(2):141-153. https://doi.org/10.1111/j.1365-2486.2006.01067.x

Valentine H (1999) Estimation of the net primary productivity of even-aged stands with a carbon-allocation model. Ecol Model 122(3):139-149. https://doi.org/10.1016/S0304-3800(99)00134-9, http://tinyurl.sfx.mpg.de/uajy

Walker AP, Hanson PJ, De Kauwe MG, Medlyn BE, Zaehle S, Asao S, Dietze M, Hickler T, Huntingford C, Iversen CM, Jain A, Lomas M, Luo Y, Mccarthy H, Parton WJ, Prentice IC, Thornton PE, Wang S, Yp Wang, Warlind D, Weng E, Warren JM, Woodward FI, Oren R, Norby RJ (2014) Comprehensive ecosystem model-data synthesis using multiple datasets at two temperate forest freeair $\mathrm{CO}_{2}$ enrichment experiments: model performance at ambient $\mathrm{CO}_{2}$ concentration. J Geophys Res Biogeo 119(5):937-964. https://doi.org/10.1002/2013JG002553

Walker AP, Zaehle S, Medlyn BE, De Kauwe MG, Asao S, Hickler T, Parton W, Ricciuto DM, Wang YP, Wårlind D, Norby RJ (2015) Predicting long-term carbon sequestration in response to $\mathrm{CO}_{2}$, enrichment: how and why do current ecosystem models differ? Global Biogeochem Cycles 29(4):476-495. https://doi.org/10.10 02/2014GB004995
Wang YP, Law RM, Pak B (2010) A global model of carbon, nitrogen and phosphorus cycles for the terrestrial biosphere. Biogeosciences 7(7):2261-2282. https://doi.org/10.5194/bg-7-2261-2010

Waring R, Running S (1998) Forest ecosystems: analysis at multiple scales. No. v 1 in Forest ecosystems: analysis at multiple scales, Academic Press. https://books.google.de/books? id=91fwAAAAMAAJ

Weng E, Dybzinski R, Farrior CE, Pacala SW (2019) Competition alters predicted forest carbon cycle responses to nitrogen availability and elevated $\mathrm{CO}_{2}$ : simulations using an explicitly competitive, game-theoretic vegetation demographic model. Biogeosciences 16(23):4577-4599. https://doi.org/10.5194/bg-16-4577-2019, https://www.biogeosciences.net/16/4577/2019/

Williams M, Schwarz PA, Law BE, Irvine J, Kurpius MR (2005) An improved analysis of forest carbon dynamics using data assimilation. Glob Chang Biol 11(1):89-105. https://doi.org/10.1111/j. 1365-2486.2004.00891.X

Xia J, Luo Y, Wang YP, Hararuk O (2013) Traceable components of terrestrial carbon storage capacity in biogeochemical models. Glob Chang Biol 19(7):2104-2116. https://doi.org/10.1111/gcb. 12172

Xia J, Yuan W, Wang YP, Zhang Q (2017) Adaptive carbon allocation by plants enhances the terrestrial carbon sink. Sci Rep 7(3341). https://doi.org/10.1038/s41598-017-03574-3

Zaehle S, Friend AD (2010) Carbon and nitrogen cycle dynamics in the o-CN land surface model: 1 . Model description, site-scale evaluation, and sensitivity to parameter estimates. Glob Biogeochem Cycles 24(1):1-13. https://doi.org/10.1029/2009GB003521

Zhang Z, Babst F, Bellassen V, Frank D, Launois T, Tan K, Ciais P, Poulter B (2017) Converging climate sensitivities of european forests between observed radial tree growth and vegetation models. Ecosystems 21(3):410-425. https://doi.org/10.1007/s10021017-0157-5

Zobeley J, Lebiedz D, Kammerer J, Ishmurzin A, Kummer U (2005) A new time-dependent complexity reduction method for biochemical systems. In: Transactions on computational systems biology I, Springer, pp $90-110$

Publisher's Note Springer Nature remains neutral with regard to jurisdictional claims in published maps and institutional affiliations. 